\title{
Direct Interaction between the WD40 Repeat Protein WDR-23 and SKN-1/Nrf Inhibits Binding to Target DNA
}

\author{
Chi K. Leung, ${ }^{\text {a }}$ Koichi Hasegawa, ${ }^{\text {b }}$ Ying Wang, ${ }^{a}$ Andrew Deonarine, ${ }^{\text {a }}$ Lanlan Tang, ${ }^{\text {a Johji Miwa, }}{ }^{\text {b,c }}$ Keith P. Choe ${ }^{\text {a }}$ \\ Department of Biology and Genetics Institute, University of Florida, Gainesville, Florida, USAa; Department of Environmental Biology, College of Bioscience and \\ Biotechnology, Chubu University, Kasugai, Aichi, Japanb; Academy of Arts and Sciences, Chubu University, Kasugai, Aichi, Japan
}

\begin{abstract}
SKN-1/Nrf transcription factors activate cytoprotective genes in response to reactive small molecules and strongly influence stress resistance, longevity, and development. The molecular mechanisms of SKN-1/Nrf regulation are poorly defined. We previously identified the WD40 repeat protein WDR-23 as a repressor of Caenorhabditis elegans SKN-1 that functions with a ubiquitin ligase to presumably target the factor for degradation. However, SKN-1 activity and nuclear accumulation are not always correlated, suggesting that there could be additional regulatory mechanisms. Here, we integrate forward genetics and biochemistry to gain insights into how WDR-23 interacts with and regulates $S K N-1$. We provide evidence that WDR-23 preferentially regulates one of three SKN-1 variants through a direct interaction that is required for normal stress resistance and development. Homology modeling predicts that WDR-23 folds into a $\beta$-propeller, and we identify the top of this structure and four motifs at the termini of SKN-1c as essential for the interaction. Two of these SKN-1 motifs are highly conserved in human Nrf1 and Nrf2 and two directly interact with target DNA. Lastly, we demonstrate that WDR-23 can block the ability of SKN-1c to interact with DNA sequences of target promoters identifying a new mechanism of regulation that is independent of the ubiquitin proteasome system, which can become occupied with damaged proteins during stress.
\end{abstract}

D uring detrimental conditions, cells mount conserved gene expression responses to limit and repair damage. These inducible stress responses play important roles in decreasing or delaying stress and age-related diseases but must also be tightly regulated under basal conditions when the response can be detrimental. Members of the "cap'n' collar" (CNC) transcription factor family are strongly induced by stress and activate a battery of genes that promote redox homeostasis, small-molecule detoxification, protein turnover, and cell differentiation and, in turn, promote organ development, stress resistance, and longevity (1). Constitutive $\mathrm{CNC}$ activity can be detrimental to reproduction and development $(2,3)$, and tight regulation is thought to be achieved by controlling nuclear abundance, stability, posttranslational modification, and negative feedback (1, 3-8). Mammalian Nrf2 is the best studied inducible $\mathrm{CNC}$ and is a popular therapeutic target for multiple age- and stress-related diseases (9-11). Nrf2 is regulated by a redox-sensitive ubiquitin ligase adaptor named Keap1 (5). Additional molecular mechanisms of regulating Nrf2 and other CNCs are poorly understood.

Caenorhabditis elegans has a single functional CNC gene named skn-1 that is essential for embryonic development and promotes stress resistance and longevity under diverse conditions (12-15). By promoting redox homeostasis and small-molecule detoxification, SKN-1 is also a potential pharmacological target for host defense and drug resistance in parasitic nematodes (16, 17). The $s k n-1$ locus encodes three splice variants-SKN-1a, SKN$1 \mathrm{~b}$, and SKN-1c-with distinct expression patterns and functions. Little is known about SKN-1a, but it has been implicated in the endoplasmic reticulum stress response (18), SKN-1b is constitutively expressed in a single pair of sensory neurons with possible secretory functions, where it is required for dietary restriction to extend life span (19), and SKN-1c accumulates in intestinal nuclei during some types of stress where it activates antioxidant and detoxification genes (7); SKN-1c and SKN-1a may share functions, because the former is completely contained within the latter
(Fig. 1A). Multiple protein kinase pathways have been postulated to regulate SKN-1c or SKN-1a subcellular distribution by unknown mechanisms $(6,13,20-22)$.

We previously determined that Keap 1 is absent from C. elegans and other nematodes (16) and identified WDR-23, a conserved WD40 repeat protein, as a direct repressor of SKN-1 $(8,23,24)$. Transcriptional and translational green fluorescent protein (GFP) reporters suggest that WDR-23 is expressed in many tissues, including the intestine, and regulates SKN-1 activity cell autonomously $(8,23)$. The expression of WDR-23 in the intestine rescues motility defects and resistance to the drug aldicarb (25). WD40 repeat domains fold into $\beta$-propellers with multiple surfaces available to interact with proteins, peptides, and DNA and have been reported to function in signal transduction, protein turnover, and gene expression (26). The WD40 repeat domain is found in all eukaryotes and is the fourth most common in the human proteome (26). WD40 repeat containing proteins have been reported to regulate gene expression by two mechanisms: (i) recruiting transcriptional regulators and histone modifying proteins to chromatin and (ii) recruiting transcription factors to ubiquitin ligases $(27,28)$. WDR-23 interacts directly with SKN-1 and the DDB-1/CUL-4 ubiquitin ligase and represses nuclear accumulation of the factor, suggesting ubiquitylation and proteosomal degradation as a likely mechanism of regulation (8). However, ex-

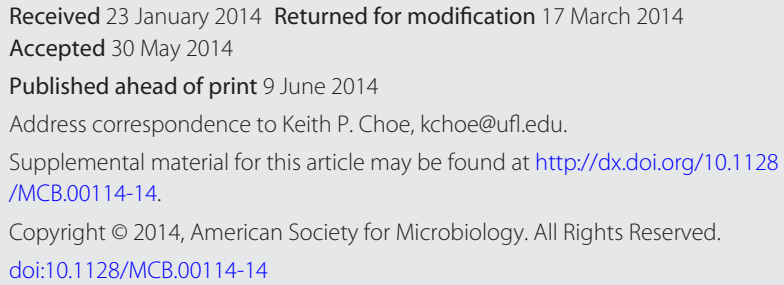




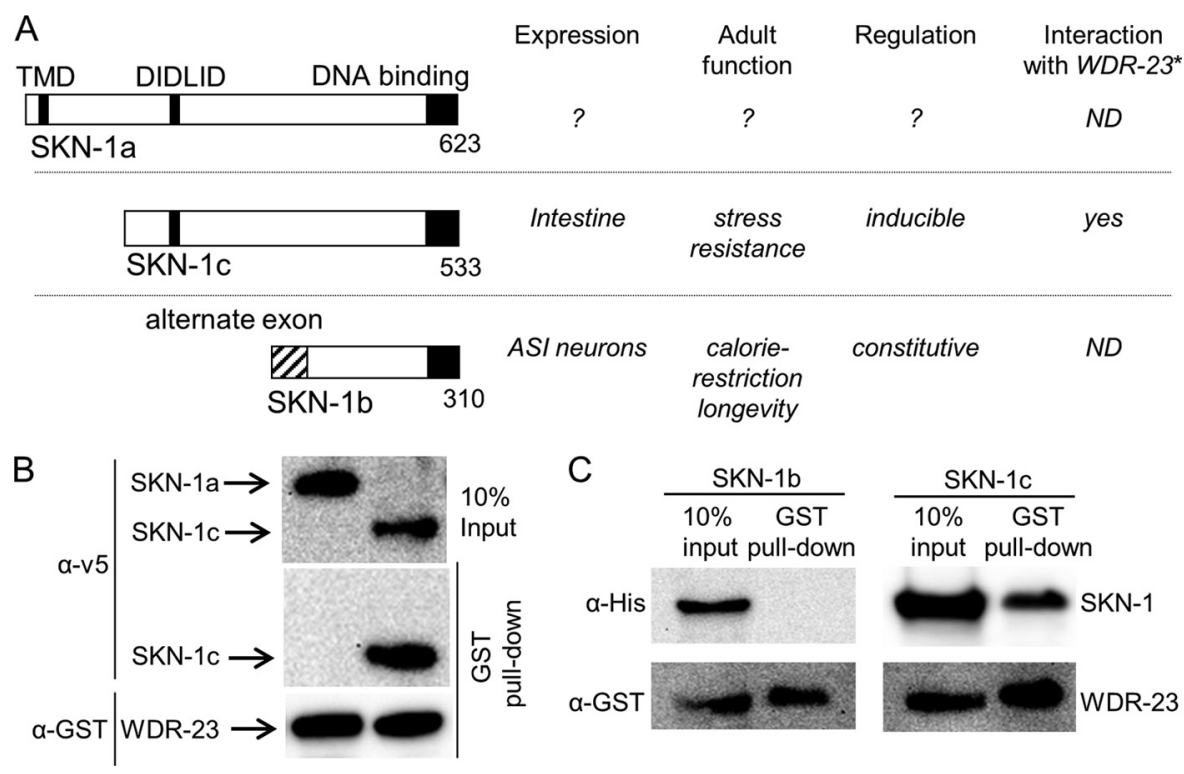

FIG 1 WDR-23 may preferentially interact with a single SKN-1 splice variant. (A) Schematic diagram of three SKN-1 splice variant proteins with a summary of properties. The amino acid number and known functional domains are marked. TMD, predicted transmembrane domain; ND, not detected; ${ }^{*}$, results from the present study. (B) Western blots of GST-WDR-23a pulldowns from HEK293T cells. (C) Western blots of GST-WDR-23a pulldowns with SKN-1b and SKN-1c expressed in bacteria with a $\mathrm{His}_{6}$ tag. $\alpha$, antibody against.

pression of SKN-1 target genes does not always correlate with SKN-1 accumulation in the nucleus $(15,18,29)$. Furthermore, silencing of $w d r$-23 causes far greater (5- to 7-fold) activation of SKN-1-regulated promoter reporters than silencing of $d d b-1$, cul-4, or proteasome subunits (8), suggesting that WDR-23 may partly regulate SKN-1 independently of the ubiquitin ligase.

It is not known whether WDR-23 preferentially regulates specific SKN-1 variants, and nothing is known about how the proteins interact. It is also not known whether WDR-23 can regulate SKN-1 by mechanisms independent of the ubiquitin proteasome system or whether WDR-23 regulation of SKN-1 activity, stress resistance, longevity, and development are all mediated by a direct interaction between the proteins. Here, we biochemically characterize the interaction between WDR-23 and SKN-1 and test its physiological importance in vivo. We were only able to detect interaction with SKN-1c, suggesting preferential regulation of this variant. Genetic screening for SKN-1 activation yielded one skn-1 dominant allele and three $w d r-23$ missense alleles that interrupt the interaction. We identify multiple regions and conserved motifs within SKN-1c that contribute to its interaction with WDR23, a finding consistent with multiple contact points. Surprisingly, we find that the conserved basic regions of SKN-1c are required for the interaction and that interactions between the proteins block SKN-1c from binding target DNA, suggesting a new mechanism of SKN-1 regulation that is independent of the ubiquitin proteasome system. Lastly, we demonstrate that loss of the SKN1/WDR-23 interaction alone strongly elevates SKN-1 nuclear abundance, activates SKN-1 target genes, increases stress resistance and longevity, and delays larval development.

\section{MATERIALS AND METHODS}

C. elegans strains. Strains are listed in the supplemental material. Unless noted otherwise, worms were cultured at $20^{\circ} \mathrm{C}$ according to standard methods (30).
Yeast assays. Yeast experiments were performed as previously described $(3,8)$, with some modifications. For yeast two-hybrid assays, 500 ng of each plasmid was transformed into strain MaV203 (Invitrogen, Indianapolis, IN) according to the manufacturer's protocol. Interaction strength was quantified with a $\beta$-galactosidase assay (Pierce/Thermo Scientific, Rockford, IL). The activity was calculated in Miller units (31), normalized to controls, and then expressed as the relative activity. For yeast one-hybrid assays, a 528-bp fragment of the $w d r-23$ promoter (bp -1024 to -496 relative to the start codon of $w d r-23 a$ ) containing three functional SKN-1 binding elements (SBEs) (3) and a 727-bp fragment of the gst-4 promoter upstream of the start codon containing two putative SBEs were PCR amplified and ligated into the pHISi site of the pLacZi vector (a gift from King L. Chow, Hong Kong University of Science and Technology). Each clone was linearized with either XhoI (pHISi) or ApaI ( $\mathrm{pLacZi}$ ) and used for transformation and integration into the yeast strain YM4271 (National Bioresource Project, Japan). Integration was confirmed by plating on auxotrophic media.

GST pulldown and IP. HEK293T cells were cultured in Dulbecco modified Eagle medium with 10\% fetal bovine serum, $4.5 \mathrm{~g} /$ liter glucose, $584 \mathrm{mg} /$ liter L-glutamine, $100 \mathrm{mg} /$ liter sodium pyruvate, $100 \mathrm{U} / \mathrm{ml}$ penicillin, and $100 \mu \mathrm{g} / \mathrm{ml}$ streptomycin. Transfections were performed with Lipofectamine LTX and PLUS (Life Technologies, Grand Island, NY) on fibronectin-coated six-well plates. At 2 days after transfection, the cells were rinsed twice with ice-cold phosphate-buffered saline (PBS) and lysed with immunoprecipitation (IP) lysis buffer (Pierce, Rockford, IL) supplemented with Halt protease inhibitor single-use cocktail (Pierce); insoluble components were removed by centrifugation $(16,000 \times g$ for $20 \mathrm{~min}$ at $4^{\circ} \mathrm{C}$ ). Glutathione $S$-transferase (GST) pulldown experiments were performed as described previously (8) with slight modifications. Lysates were mixed with a slurry of glutathione-Sepharose 4B (GE Healthcare, Piscataway, $\mathrm{NJ}$ ), and the binding reaction mixture was incubated for $4 \mathrm{~h}$ at $4^{\circ} \mathrm{C}$. For IP, the lysates were precleared with protein A/G Plus-agarose (Santa Cruz, Santa Cruz, CA) at $4^{\circ} \mathrm{C}$ for $2 \mathrm{~h}$. IPs used $1 \mu \mathrm{g}$ of v 5 antibody according to the manufacturer's protocol (Life Technologies). After the addition of protein $\mathrm{A} / \mathrm{G}$-agarose beads, the incubation was continued at $4^{\circ} \mathrm{C}$ for $2 \mathrm{~h}$ with agitation. For hybrid protein-protein interaction assays, His-tagged SKN-1b and SKN-1c (vector pDEST17; Life Technologies) were ex- 
pressed in BL21(DE3) cells and mixed with HEK293T lysates containing GST-WDR-23a at $4^{\circ} \mathrm{C}$ overnight.

Beads from pulldowns and IPs were washed extensively with PBS and eluted with sodium dodecyl sulfate (SDS) loading buffer by heating at $70^{\circ} \mathrm{C}$ for $15 \mathrm{~min}$. Immunoblotting of v5-tagged (catalog no. R960-25, Invitrogen) and untagged SKN-1 were performed as previously described (8). Other antibodies were mouse antitubulin monoclonal antibody (MAb) E7 (1:100; Developmental Studies Hybridoma Bank, Iowa City, IA), rabbit anti-histone H3 MAb (1:500; catalog no. 4499; Cell Signaling, Danvers, MA), mouse anti-GST MAb (1:1,000; catalog no. B-14; Santa Cruz), and mouse anti-His MAb (1:1,000; catalog no. H-3; Santa Cruz). Blots were visualized with a FluorChem E imager (ProteinSimple, Santa Clara, CA). SKN-1a::GFP protein bands were quantified with ImageJ (32) and reported relative to tubulin.

Generation of transgenes and transgenic worms. The $P w d r-23$ (-SBE)::skn-1a::GFP translational GFP reporter was generated in vector pDEST DD04 using Gateway cloning (Life Technologies). Germ line transformation was performed according to standard methods, and at least three independent transgenic lines were analyzed.

Microscopy and GFP quantification. Low-magnification bright-field and fluorescence images were captured with a Nikon SMZ800 microscope. Differential interference contrast and high-magnification fluorescent images were taken of worms with an Olympus BX60 microscope. Fluorescence was quantified from the photomicrographs with a nematode image analyzer FL (v1.0.0.1) as described previously (http://www.vision .cs.chubu.ac.jp/fl1001/ [33]).

Nuclear extract preparation. Nuclear and cytosolic extracts were prepared as previously described (34) with some modifications. Briefly, synchronized L4 to young adult stage worms were collected from five NA22seeded NGM plates and washed in NGM buffer, followed by lysis buffer (10 mM HEPES [pH 7.1], $5 \mathrm{mM} \mathrm{MgCl}_{2}, 2 \mathrm{mM}$ dithiothreitol [DTT], 10\% glycerol, and $1 \times$ Halt protease inhibitor single-use cocktail [Pierce]). Worms in extract buffer were dripped into liquid $\mathrm{N}_{2}$ and ground in a mortar. Worm dust was thawed on ice and sheared with a Dounce homogenizer (30 strokes, pistol B). Crude extracts were centrifuged at $13,000 \times g$ for $15 \mathrm{~min}$ to obtain a soluble cytosolic supernatant. The pellet was washed twice with extract buffer and solubilized in $1 \times$ SDS loading buffer to obtain the nuclear fraction.

Protein modeling and alignment. A model of WDR-23 was generated for amino acids 146 to 571 in the Phyre ${ }^{2}$ online modeling tool (35). The resulting model was annotated with Geneious Pro v5.6.5. SKN-1 and Nrf protein alignments were generated with the MAFFT (v6.814b) algorithm E-INS-i and annotated with Geneious Pro v5.6.5.

In vitro DNA binding. Immunoprecipitated v5-SKN-1c or v5-LacZ was incubated with $100 \mathrm{ng}$ of DNA probe in DNA binding buffer $(100 \mathrm{mM}$ Tris, $500 \mathrm{mM} \mathrm{KCl}, 10 \mathrm{mM}$ DTT [pH 7.5]) supplemented with $1 \mu \mathrm{g}$ of poly (dI-dC) at $4^{\circ} \mathrm{C}$ overnight. Wild-type and mutant GST-WDR-23a proteins were eluted from glutathione beads with $10 \mathrm{mM}$ reduced glutathione in $50 \mathrm{mM}$ Tris- $\mathrm{Cl}$ ( $\mathrm{pH}$ 8.0). Equal amounts of tagged SKN-1 or WDR-23 proteins, determined by immunoblotting, were added. Unbound free probe was removed by washing with ice-cold PBS and centrifugation at $600 \times \mathrm{g}$ for $2 \mathrm{~min}$ at $4^{\circ} \mathrm{C}$. Protein A/G-Sepharose was resuspended in $400 \mu \mathrm{l}$ of PBS and heated to 80 to $90^{\circ} \mathrm{C}$ for $10 \mathrm{~min}$. The DNA was eluted and cleaned by using phenol-chloroform extraction and ethanol precipitation. Eluted DNA was quantified as described previously (3) with nested primers (forward, 5'-ACGAGTGAAAGACGCGTGAA; reverse, $5^{\prime}$-TGTTCGTTTTGACCCTTACGG).

In vivo assays. Juglone survival, longevity, and larval progression assays were conducted as described previously (3).

Statistical analyses. Statistical significance was determined using oneway analysis of variance with a Dunnett's or Tukey's post hoc test when three or more means were compared. Chi-square tests were used to evaluate categorical data, and log rank tests were used to compare survival curves. $P$ values of $<0.05$ were taken to indicate statistical significance.

\section{RESULTS}

WDR-23 may preferentially regulate $\mathrm{SKN}-1 \mathrm{c}$. We previously identified the WD40 repeat protein WDR-23 as a principal repressor of the SKN-1 transcriptional response in a genome-wide RNA interference (RNAi) screen and demonstrated that WDR-23 functions with the DDB-1/CUL-4 ubiquitin ligase to regulate SKN-1 protein levels and nuclear accumulation (8). SKN-1a, SKN-1b, and SKN-1c share the same C terminus and DNA-binding domain but have distinct $\mathrm{N}$ termini (Fig. 1A).

The $w d r$-23 locus is also thought to encode splice variants. We focused on the longest, WDR-23a, because it is the only one that has been shown to regulate SKN-1 activity in vivo (23). We previously demonstrated robust interaction between WDR-23a and SKN-1c using GST pulldowns (8). As shown in Fig. 1B (right lane), GST-WDR-23a pulled down high levels of v5-tagged SKN1c. Alternatively, we did not detect any pulldown of v5-SKN-1a (left lane) despite high levels of this longer variant in the input lysate; longer exposures of the imaging camera also failed to detect any pulldown of v5-SKN-1a (data not shown). v5-SKN-1b was expressed poorly in transfected HEK293T cells, so we instead expressed recombinant His-tagged SKN-1b in Escherichia coli, mixed bacterial lysates with HEK293T lysates expressing GSTWDR-23a, and performed GST pulldown followed by Western blotting. As shown in Fig. 1C, His-SKN-1b and His-SKN-1c were both expressed well in bacteria, but only His-SKN-1c was detected in pulldowns with GST-WDR-23a. Longer exposures of the imaging camera also failed to detect pulldown of His-SKN-1b (data not shown).

We next investigated $w d r-23$ regulation of SKN-1a or SKN-1b protein in vivo. Because we wanted to test for regulation by $w d r$ 23, we expressed SKN-1a::GFP with the $w d r-23$ promoter to ensure coexpression. A complication with this approach is that the $w d r-23$ promoter is activated by SKN-1 directly via three SBEs during $w d r$-23 loss of function (3); therefore, we mutated all three SBEs in the transgene promoter, which disables this feedback loop (3). We generated three independent $s k n-1 a(\mathrm{cDNA}):: \mathrm{GFP}$ reporter lines driven by the mutant $w d r-23$ promoter. Consistent with the activity of the $w d r-23$ promoter (3), this ectopic $s k n$ $1 a$ (cDNA)::GFP fusion protein was expressed in many tissues, including head neurons, the pharynx, the ventral nerve cord, and tail neurons (see Fig. S2 in the supplemental material). The three $s k n$ 1a::GFP extrachromosomal arrays were then crossed with the $w d r-23(t m 1817)$-null allele. Loss of $w d r-23$ had no obvious effect on GFP distribution or intensity (see Fig. S2 in the supplemental material), but the broad distribution of the transgene made it difficult to quantify within individual worms. We also cannot rule out the possibility of SKN-1a::GFP being cleaved to SKN-1c::GFP and contributing to fluorescence. Therefore, we instead compared GFP levels in Western blots of lysates from transgenic worm populations. There was no effect of $w d r-23(t m 1817)$ in three separate lines with various levels of basal expression (Fig. 2A, wild-type/ $w d r-23$ mutant ratio of $1.014 \pm 0.039)$. The apparent molecular mass of these bands $(\sim 100 \mathrm{kDa})$ matches the prediction for fulllength SKN-1a::GFP.

We next sought to determine whether $w d r-23$ is coexpressed with $s k n-1 b$ in ASI neurons, the cells in which $s k n-1 b$ functions to promote longevity during calorie restriction (19). Transcriptional $P w d r-23:: G F P$ reporters are expressed in numerous head neurons $(3,8)$, but individual neurons are difficult to distinguish without 
A

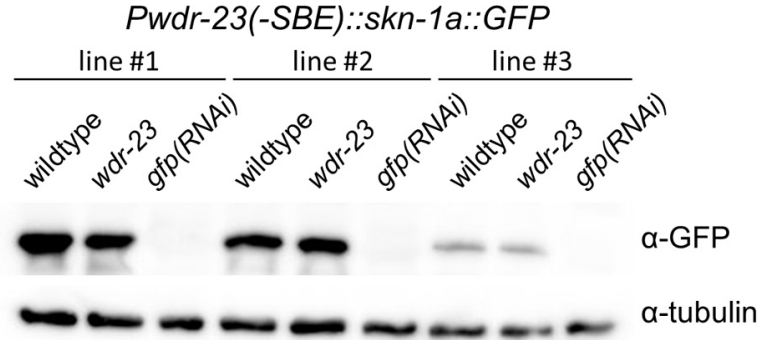

B DIC

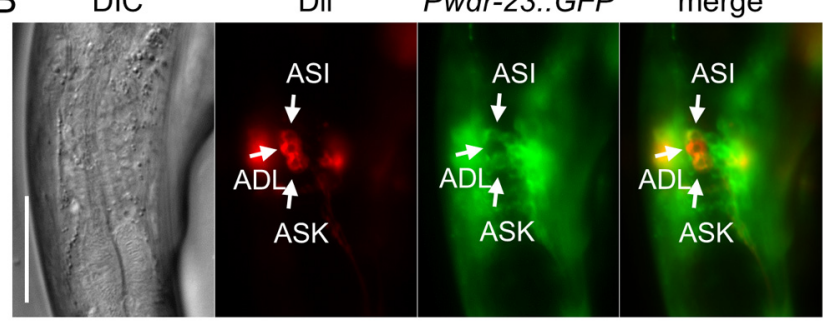

C
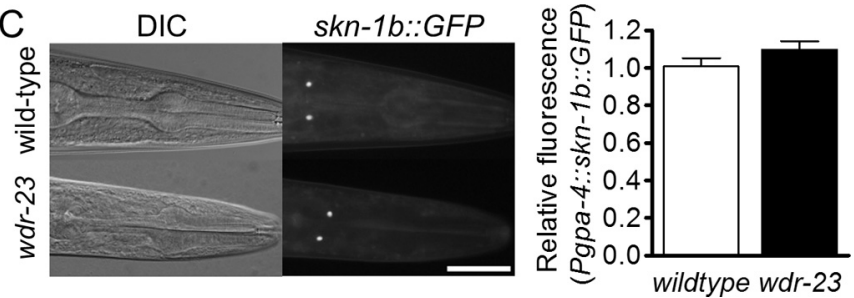

FIG $2 w d r-23$ may preferentially regulate a single $\mathrm{SKN}-1$ splice variant in vivo. (A) Western blot of SKN-1a::GFP $(\sim 100 \mathrm{kDa})$ in wild type and in $w d r-$ 23(tm1817) mutants. $g f p$ (RNAi) was included as a control for specificity of the GFP antibody. Tubulin was included as a loading control. $\alpha$, antibody against. (B) Representative micrographs of worms expressing Pwdr-23a::GFP stained with Dil. Three amphid neurons (ASI, ADL, and ASK) were labeled. Scale bar, $20 \mu \mathrm{m}$. (C) On the left are representative paired differential interference contrast (DIC) and fluorescent micrographs of wild-type and wdr-23(tm1817) worms expressing Pgpa-4::skn-1b::GFP. Scale bar, $50 \mu \mathrm{m}$. On the right are shown the relative GFP fluorescence results for the two ASI neurons in wildtype and $w d r-23(t m 1817)$ worms. Values are means plus standard errors $(n=$ 65 or 66 L4 to young adult stage worms).

costaining. The lipophilic dye DiI stains ciliated amphid neurons, including ASI (36). We stained three independent $P w d r-23:: G F P$ transcriptional reporter lines with Dil and observed consistent overlap of signal in ASI neurons (Fig. 2B), indicating that $w d r-23$ is coexpressed with $s k n-1 b$. We then crossed a functional and chromosomally integrated SKN-1b::GFP reporter driven by an ASI-specific gpa-4 promoter (19) with $w d r-23(t m 1817)$ and measured the GFP fluorescence. As shown in Fig. 2C, loss of $w d r-23$ had no effect on SKN-1b::GFP fluorescence.

Taken together, the data in Fig. 1 and 2 suggest that WDR-23 may preferentially interact with and regulate SKN-1c, and we focus the remainder of the present study on this isoform. It is also important to note that we cannot rule out the possibility that WDR-23 interacts with or regulates SKN-1a or SKN-1b at undetectable levels or under conditions that are different from SKN-1c.

Xenobiotic response mutations reduce protein stability and disrupt interactions between SKN-1c and WDR-23a. We next investigated the interaction between WDR-23a and SKN-1c to gain molecular insights into how the WD40 repeat protein regulates the transcription factor. We previously reported five alleles of $w d r-23$ from a chemical mutagenesis screen for xenobiotic response (xrep) mutants that constitutively express transgenic reporters for detoxification genes regulated by SKN-1 (23). In the present study, we mapped and sequenced five additional xrep alleles that encode $w d r-23$ point mutations (Fig. 3A and see Fig. S1 in the supplemental material). Six of the sequenced $w d r-23$ alleles encode amino acid substitutions, and four introduce premature termination codons. Importantly, 21 of 24 total xrep mutations map to $w d r-23$, verifying that this gene is a central regulator of both SKN-1 and xenobiotic responses. Interestingly, one of the xrep mutations mapped to $s k n-1$ as an R41-to-C substitution at the $\mathrm{N}$ terminus of SKN-1c (Fig. 3A). Similar to the $w d r-23$ lossof-function mutation, $s k n-1(k 1023)$ constitutively and strongly activates multiple detoxification genes ( $g s t-4, g s t-7, g s t-30$, and C02D5.4) regulated by SKN-1 (Fig. 3C and see Fig. S3 in the supplemental material). This allele, $s k n-1$ (k1023), also activates $g s t-4$ reporters as a heterozygote ( $\mathrm{K}$. Hasegawa et al., unpublished results), confirming that it is a gain of function.

We measured in vivo gst-4::GFP fluorescence in all 10 sequenced $w d r-23$ mutants and the single $s k n-1$ mutant to confirm pathway activation; gst-4 is a core SKN-1 target gene that is strongly activated in multiple tissues under numerous stress conditions $(8,16,18,37)$. As shown in Fig. $3 \mathrm{~B}$ and $\mathrm{C}$, the reporter was constitutively activated in all mutants $(P<0.001)$ at variable levels. We list mutants here by the amino acid substitution they encode; allele names are given in Fig. S1 in the supplemental material.

WDR-23 mutations could destabilize the protein. Western blots with an antibody raised against a highly conserved region of human WDR23 detected a band in worm lysates that matches the predicted size of WDR-23a ( $\sim 65 \mathrm{kDa})$ (Fig. 3D); this band was eliminated by a deletion allele of $w d r-23(\mathrm{tm} 1817)$ and was reduced $90 \%$ by $w d r-23$ (RNAi), suggesting that it does specifically recognize C. elegans WDR-23. The intensities of four missense mutant WDR-23 bands were reduced 40 to $50 \%$ relative to the wild type (Fig. 3D), suggesting that these mutations affect protein stability. However, we speculated that an approximately 40 to $50 \%$ reduction of WDR-23 levels might not completely explain the strong induction of SKN-1 in these mutants (Fig. 1B) because $w d r$ $23(\mathrm{tm} 1817)$ heterozygous worms (with only one copy of $w d r-23$ ) do not activate gst-4::GFP reporters (K. P. Choe et al., unpublished results). Given that many WD40 repeat proteins function as scaffolds (8), we hypothesized that at least some of the WDR-23 missense mutations might also disrupt interactions with SKN-1c. As shown in Fig. 3E, three of these mutations reduced the pulldown of SKN-1c to below detectable levels. Therefore, these mutations partially reduce WDR-23 protein levels and dramatically reduce interactions with SKN-1c.

The SKN-1(R41C) mutation could potentially activate target gene transcription by WDR-23-dependent or WDR-23-independent mechanisms. Notably, a recent study identified two other missense alleles that activate $\mathrm{SKN}-1$ by a mechanism hypothesized to be independent of WDR-23 (38). As shown in Fig. 3F, we were not able to detect pulldown of SKN-1(R41C) by wild-type GSTWDR-23a. R41 of SKN-1c could play an important role in the interaction with WDR-23, or the introduction of a cysteine could disrupt interactions with WDR-23 by introducing a non-native disulfide bond. An R41 substitution with alanine (R41A) also disrupted the interaction (Fig. $3 \mathrm{~F}$ ), demonstrating the requirement of arginine at this position. 

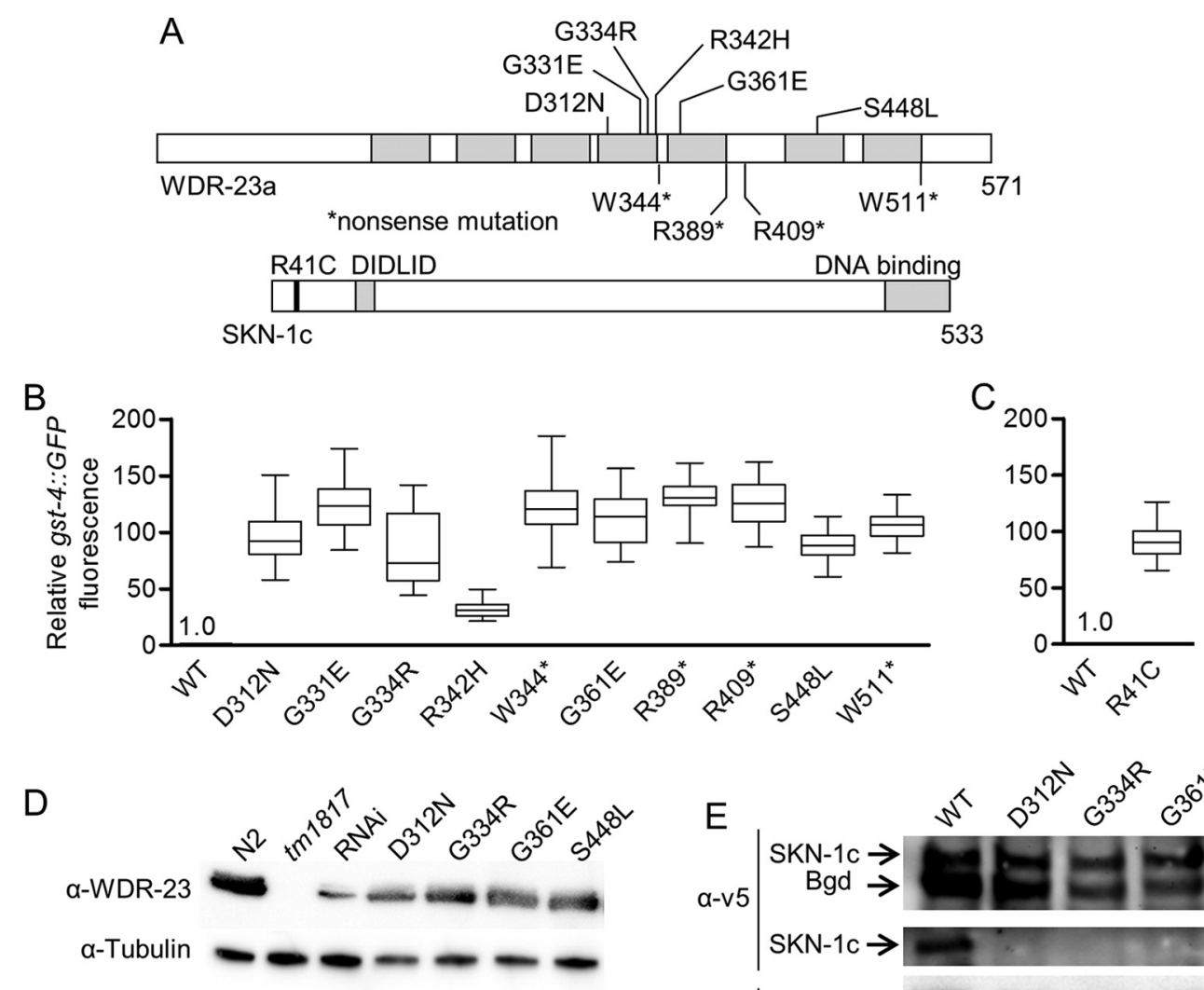

WDR-23/tubulin $\quad \begin{array}{lllllll}1.0 & 0.0 & 0.1 & 0.5 & 0.6 & 0.5 & 0.5\end{array}$
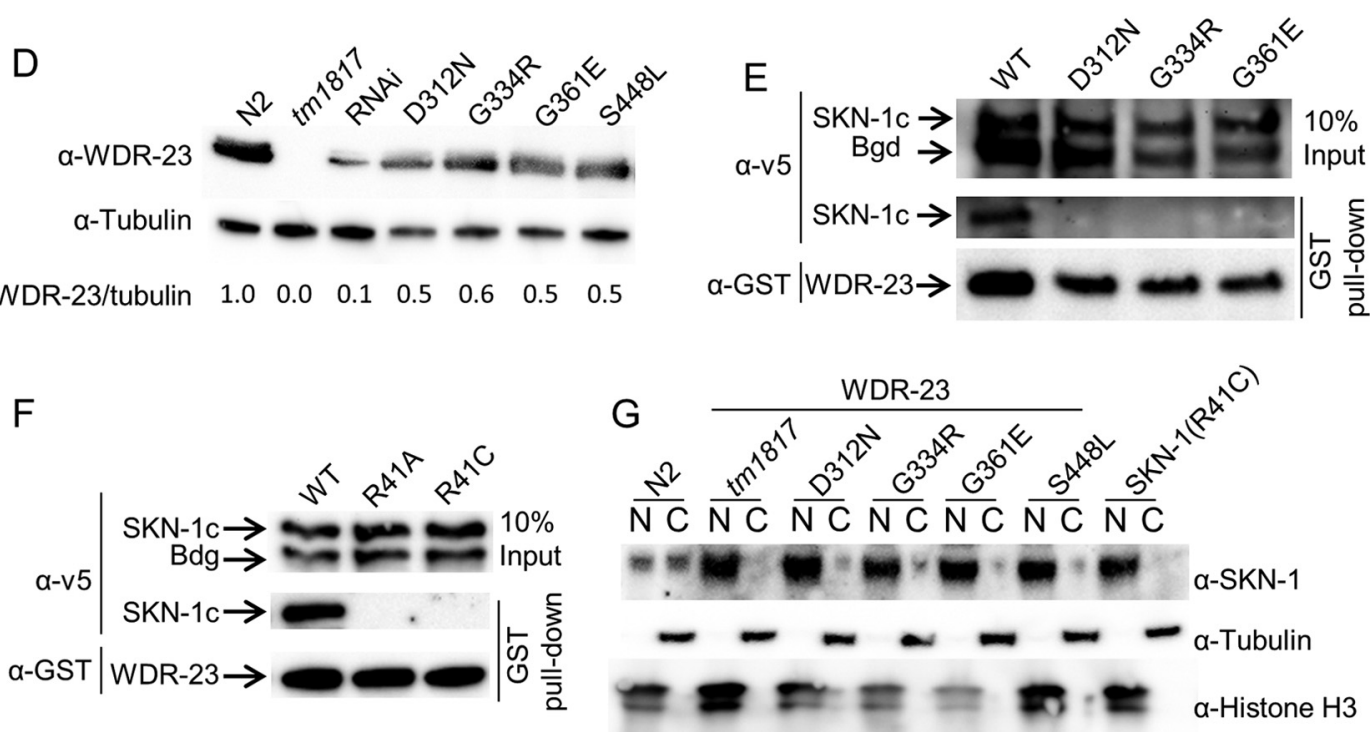

FIG 3 Multiple xenobiotic response mutations map to $w d r-23$ and $s k n-1$. (A) Models of WDR-23a and SKN-1c proteins with mutations and known motifs and domains marked. Gray areas of WDR-23a are WD40 repeats. DIDLID is a region of SKN-1 that is highly conserved and required for transactivation (52). (B and C) Quantification of $g s t-4:: G F P$ reporter activity in $10 w d r-23$ and $1 s k n-1$ mutant strains. Box plots mark median and first and third quartiles and whiskers mark ranges ( $n=21$ to 66 worms, $P<0.001$ relative to the wild type [WT] for all mutants). (D) Western blots of WDR-23 and tubulin from worm lysates; $w d r-23(\mathrm{tm} 1817)$ is a deletion allele, and the RNAi was against $w d r-23$. The numbers below lanes are WDR-23 band intensities relative to tubulin bands. (E and F) Western blots of v5::SKN-1c ( $\sim 65 \mathrm{kDa})$ and GST::WDR-23a ( $\sim 90 \mathrm{kDa})$ from lysate (top) and GST pulldowns (bottom). Bgd, background band. (G) Western blot of nuclear and cytosolic fractions of endogenous SKN-1 in five $w d r-23$ mutants and one $s k n-1$ mutant. Histone H3 is a nuclear fraction marker and tubulin is a cytosolic marker. $\alpha$, antibody against.

Xenobiotic response mutations cause SKN-1 to translocate into the nucleus. Previous studies with transgenic SKN-1::GFP fusion proteins expressed from multicopy arrays suggest that SKN-1 is regulated in part by nuclear translocation $(7,8,29,39)$. We previously demonstrated that the loss of $w d r-23$ increases the nuclear abundance of SKN-1::GFP (8). To avoid potential fusion protein and overexpression artifacts, we used differential centrifugation and Western blots of endogenous SKN-1 $(8,40)$ to determine whether missense mutations alter nuclear abundance of the transcription factor. As shown in Fig. 3G, SKN-1(R41C) and four missense $w d r-23$ alleles all caused a dramatic increase of SKN-1 in nuclear fractions. These mutations also appear to increase total SKN-1 levels, similar to our previous observations with $w d r$ 23(tm1817) (8); the apparent molecular mass $(\sim 65 \mathrm{kDa})$ of the prominent band matches $\mathrm{SKN}-1 \mathrm{c}$ expressed heterologously (8).

WDR-23 folds into a $\beta$-propeller with multiple blades that contribute to the interaction with SKN-1c. The data in Fig. 3 identify mutations in WDR-23a that disrupt interactions with SKN-1c in vitro. We next used these mutations together with computational modeling to gain insights on the structure of WDR-23 and how it interacts with SKN-1. Protein modeling using known structures of homologous proteins as the templates is currently 

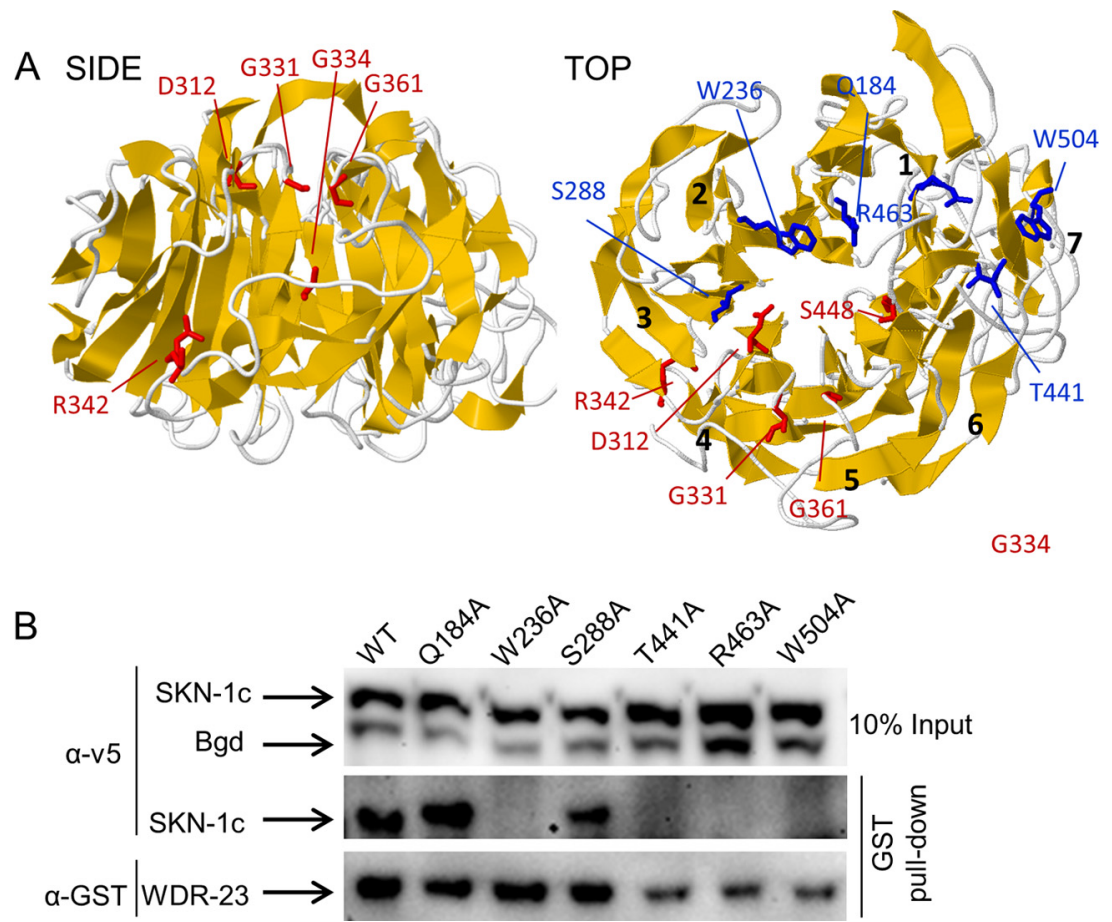

FIG 4 WDR-23 folds into a $\beta$-propeller with multiple blades that contribute to SKN-1c interactions. (A) Side and top views of a Phyre ${ }^{2}$-predicted threedimensional structure of WDR-23. Four missense WDR-23a mutations (red) map to the top, or near the top, of blades 4 and 5; mutation of D312, G334, and G361 reduced interactions with SKN-1c (see Fig. 3E). Additional residues predicted to be on the tops of WD blades (blue) are shown in the top view. (B) Western blots of v5::SKN-1c $(\sim 65 \mathrm{kDa})$ and GST::WDR-23a $(\sim 90 \mathrm{kDa})$ from lysate (top) and GST pulldowns (bottom). Bgd, background band; $\alpha$, antibody against.

the most accurate approach for structure modeling (41-44). We generated a model of the WD40 repeat region of WDR-23 with the Phyre $^{2}$ protein prediction server (35). This tool is optimized to predict structures from templates with low sequence homology, such as WD40 repeat proteins, which have very similar topology despite highly diverse sequences (45). The model for WDR-23 was predicted with $93 \%$ confidence (Fig. 4A, shown from two orientations). Similar to other WD40 repeat proteins, the predicted structure is a seven bladed $\beta$-propeller with top, bottom, and side faces available for interactions.

The top face of WD40 repeat $\beta$-propellers is commonly the site of protein-protein interactions (45). Interestingly, four of the six WDR-23 missense mutations (including three that disrupt the interaction with SKN-1c) (Fig. 3E) map to the top, or near the top, of the fourth and fifth blades (Fig. 4A), suggesting that the tops of these two blades may be specifically involved in the interaction with SKN-1. Using our model and a recently developed surface prediction sequence motif for WD40 repeat proteins (45), we selected residues from the tops of other WDR-23 blades and individually tested their requirement. As shown in Fig. 4B, mutation of residues predicted to be on the tops of three additional blades (two, six, and seven) also prevented pulldown of SKN-1c. Taken together, the results in Fig. 4 suggest that WDR-23 folds into a seven blade $\beta$-propeller with several residues on the tops of multiple blades that participate in the interaction with SKN-1.

Conserved DNA binding and transactivation motifs of SKN-1c contribute to the interaction with WDR-23a. We next investigated the structure and function of SKN-1c. The structure of the C-terminal DNA-binding domain has been solved (46). Alternatively, tertiary models of the rest of SKN-1 cannot be gen- erated because there are no structures available for it or close homologs. To identify potential regions that might be important, we first generated an alignment of C. elegans SKN-1 with human Nrfs and SKN-1 from other nematodes (Fig. 5A; see the full alignment in Fig. S4A in the supplemental material). Based on this alignment, we identified 11 short (4 to 18 amino acids) highly conserved sequence motifs; two of these motifs (DIDLID and KIRRR) were conserved in human Nrf1 and Nrf2.

We first screened multiple SKN-1c truncations in the yeast two-hybrid system but were unable to identify any single region shorter than 328 amino acids that was sufficient for the interaction with WDR-23a (see Fig. S5 in the supplemental material). Although this finding is consistent with more than one region of SKN-1c participating in the interaction with WDR-23a, we cannot rule out the possibility that truncations were simply not expressed. We next tested the requirement of the 11 short, highly conserved sequence motifs throughout SKN-1 by mutation of key residues to alanine as listed in Fig. S6A in the supplemental material. As shown in Fig. 5B, mutation of conserved motifs at both ends of the protein (GLRWRD and DIDLID; GQRKR and KIRRR) drastically reduced interactions with WDR-23a. Mutation of two other motifs (DEDL and LTEM) had smaller, but significant, effects. We also tested the requirement of these 11 motifs for binding to the $w d r-23$ and gst- 4 promoters, direct SKN-1 targets (3), in the yeast system (see Fig. S6B and C in the supplemental material) and confirmed the requirement of the basic motifs, GQRKR and KIRRR, at the $\mathrm{C}$ terminus. GQRKR and KIRRR mutant proteins retained nearly full, or full, transactivation activity in the same yeast strain, respectively, confirming that they are expressed and functional. GLRWRD and DIDLID mutant 

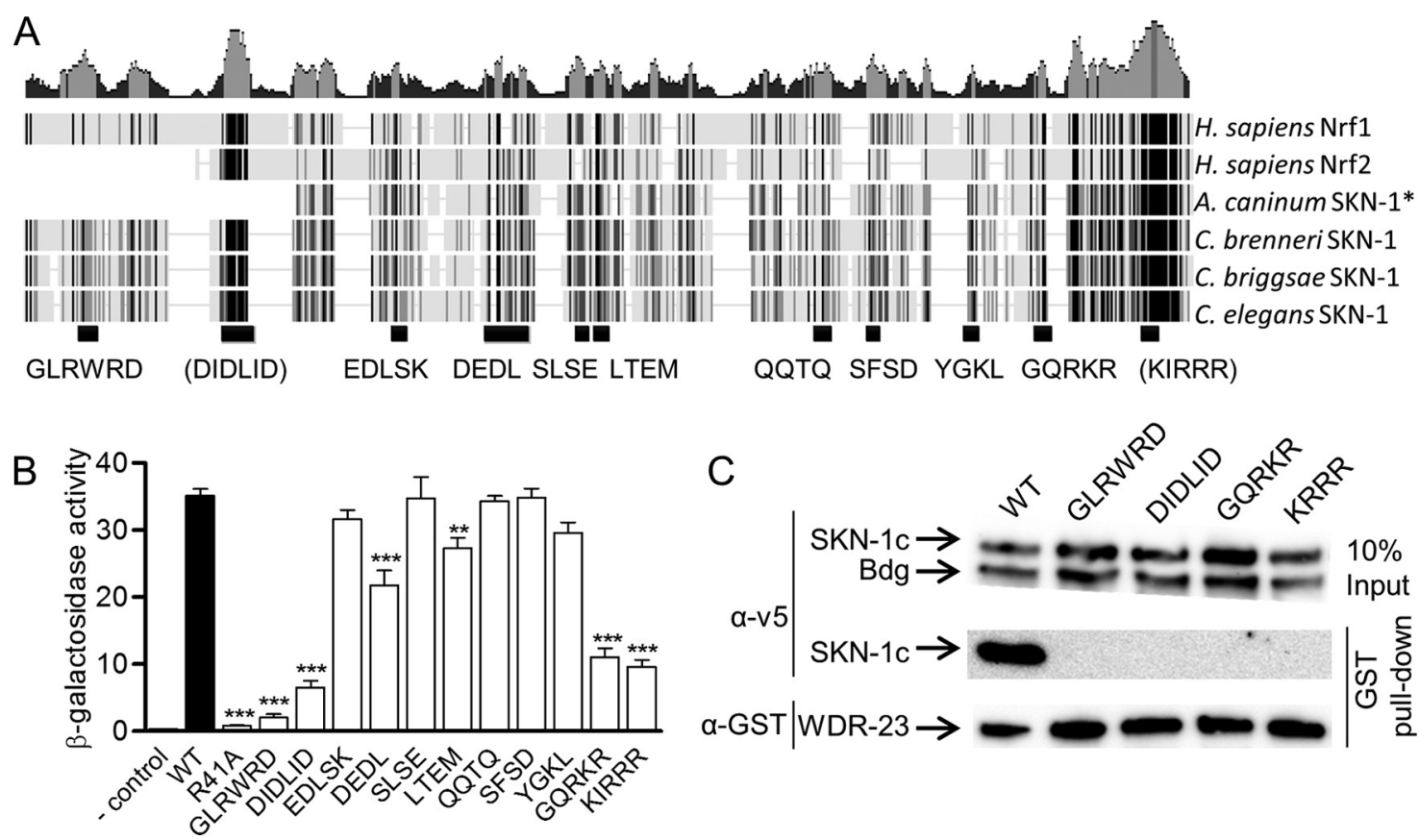

FIG 5 Multiple conserved regions of SKN-1c contribute to the interaction with WDR-23a. (A) Alignment of SKN-1/Nrf protein sequences from H. sapiens, Ancylostoma caninum, C. brenneri, C. briggsae, and C. elegans ( ${ }^{*}$, the sequence for A. caninum is partial). Eleven highly conserved motifs are labeled by key amino acid sequences (motifs in parentheses are highly conserved in human Nrfs). The plot above the alignment represents relative homology. (B) Yeast two-hybrid results for alanine mutations of the 11 highly conserved SKN-1 sequence motifs cotransfected with wild-type WDR-23a. Values are means plus standard errors ( $n=5$ colonies; ${ }^{* * *}$ and ${ }^{* *}, P<0.001$ and $P<0.01$, respectively, relative to wild-type SKN-1c). (C) Western blots of v5::SKN-1c $(\sim 65 \mathrm{kDa})$ and GST::WDR-23a ( $\sim 90 \mathrm{kDa})$ from lysate (top) and GST pulldowns (bottom). $\alpha$, antibody against.

proteins retained full binding to the $w d r-23$ promoter, confirming that they are expressed and functional. The GST pulldown system confirmed the requirement of GLRWRD, DIDLID, GQRKR, and KIRRR for interaction with WDR-23a (Fig. 5C).

WDR-23a inhibits the ability of SKN-1c to interact with target DNA. Interestingly, the results presented in Fig. 5 suggest that WDR-23a may interact directly with the well-characterized C-terminal DNA-binding domain of SKN-1c. If so, then WDR-23 might be able to interfere with DNA binding. Our previous studies demonstrated that silencing of $w d r-23$ causes far greater activation of SKN-1 than silencing of $d d b-1, c u l-4$, or proteasome subunits (8), a finding consistent with the presence of a regulatory mechanism partly independent of the ubiquitin ligase. We first tested this hypothesis with the yeast one-hybrid system by determining whether WDR-23a could inhibit the ability of $\mathrm{SKN}-1 \mathrm{c}$ to activate LacZ reporters driven by the promoters for $w d r-23$ and gst-4. As shown in Fig. 6A and B, SKN-1c (without any fusion tag) strongly activated both reporters when expressed alone. Coexpression of wild-type WDR-23a (without any fusion tag) reduced $w d r-23$ and $g s t-4$ reporter activity by 43.0 and $34.7 \%$, respectively $(P<0.001)$. Alternatively, DNA binding by the SKN-1c mutant (R41A), which did not interact with WDR-23a (Fig. 3), was independent of WDR-23a (Fig. 6C and D), suggesting that the protein-protein interaction is required for WDR-23a to inhibit DNA binding by SKN-1c.

We also tested the ability of WDR-23a to inhibit in vitro IP of target DNA by v5-tagged SKN-1c expressed from HEK293T cells. DNA probe was added to immunoprecipitated v5-SKN-1c, washed, eluted, and quantified with real-time PCR, which is more sensitive and quantitative than traditional gel-shift assays based on blotting. As shown in Fig. 6E, immunoprecipitated v5-SKN-1c was able to capture $1.14 \%$ of input probe corresponding to the $w d r-23$ promoter, which is 125 -fold greater than the negative control without v5 antibody $(P<0.001)$. We previously demonstrated that SKN-1c binds to this probe directly via three SBEs using a gel-shift assay (3). Here, mutation of these three SBEs reduced probe IP by $96 \%(P<0.001)$, confirming sequence specificity (Fig. 6E); controls with no antibody or LacZ in place of SKN-1c demonstrated protein specificity. Remarkably, adding purified GST-WDR-23a reduced wild-type probe IP by $83 \%(P<$ 0.001 ), and this effect was eliminated by mutations in WDR-23a that prevent interactions with SKN-1c (Fig. 6E). Note the equal loading of isolated GST-WDR-23a mutant proteins. WDR-23a did not affect DNA binding by SKN-1 R41A or SKN-1 R41C (Fig. 6F), which do not interact with WDR-23a (Fig. 3).

The conserved N-terminal DIDLID domain in SKN-1 mediates transcriptional activity (8). Our data suggest that DIDLID and GLRWRD may both participate in transactivation (see Fig. S6D in the supplemental material), in addition to the interaction with WDR-23a (Fig. 5), thus raising the possibility of WDR-23 affecting transcriptional activity of SKN-1. However, coexpression of WDR-23a had no effect on transcriptional activity of SKN-1 in yeast (Fig. 6G).

Taken together, the data in Fig. $6 \mathrm{~A}$ to $\mathrm{E}$ demonstrate that WDR-23a can interfere with the ability of SKN-1c to bind target DNA by a mechanism that requires direct interaction between the two proteins. Given that SKN-1 must bind to DNA to activate transcription $(3,7)$, these findings indicate that WDR-23 has the potential to regulate $\mathrm{SKN}-1$ activity independently of the ubiquitin proteasome system (8).

The SKN-1/WDR-23 interaction promotes larval development and regulates stress resistance and longevity. Our data in- 

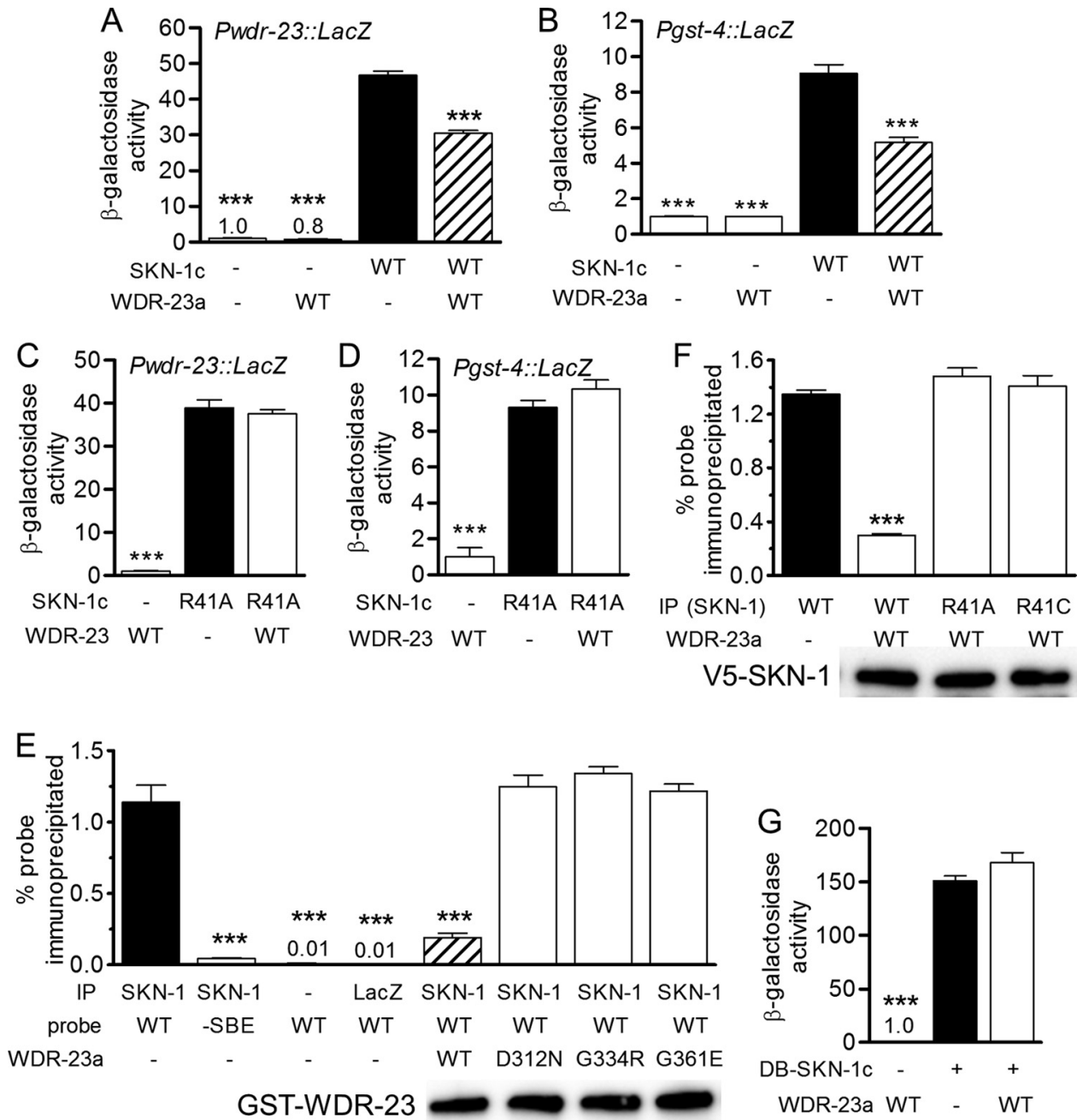

FIG 6 WDR-23a inhibits the ability of SKN-1 to interact with target DNA. (A and B) Yeast one-hybrid assays showing SKN-1c regulation of the wdr-23 (A) or gst-4 (B) promoters with or without wild-type WDR-23a. Values are means plus standard errors $\left(n=5\right.$ colonies; ${ }^{* * *}, P<0.001$ relative to the SKN-1c control without WDR-23a). (C and D) Yeast-one-hybrid assays showing SKN-1c (R41A) regulation of the wdr-23 (C) or gst-4 (D) promoters with or without wild-type WDR-23a. Values are means plus standard errors $\left(n=5\right.$ colonies; ${ }^{* *}, P<0.001$ relative to SKN-1c [R41A] without WDR-23a). (E) In vitro IP DNA assays conducted with v5-SKN-1c (SKN-1), no antibody, or v5-LacZ. The DNA probe was a 0.5-kb PCR-amplified $w d r-23$ promoter fragment containing three functional (WT) or mutated SKN-1 binding elements (-SBE) (3). In some treatments, purified wild-type or mutant GST-WDR-23a was added. The Western blot shows roughly equal input of WDR-23 proteins. Values are means plus standard errors $\left(n=3\right.$; ${ }^{* *}, P<0.001$ relative to the SKN- $1 \mathrm{c}$ and WT probe control). ( $\mathrm{F}$ ) In vitro IP DNA assays with wild-type WDR-23 and mutant SKN-1c proteins. The Western blot shows roughly equal inputs of SKN-1 protein. (G) Transactivation of UAS::LacZ by (GAL4)DB-SKN-1c with or without WDR-23a in the yeast strain MaV203. Values are means plus standard errors $\left(n=5\right.$ colonies; ${ }^{* * *}$, $P<0.001$ relative to DB-SKN-1c alone without WDR-23).

dicate that WDR-23 interacts with and regulates SKN-1c (Fig. 1 and 2) and that the protein-protein interaction can disrupt SKN-1c binding to promoter sequences of target genes (Fig. 6). Loss of $w d r-23$ by deletion or RNAi increases stress resistance and longevity and reduces the rate of larval development $(3,8,47)$. It is not known whether these functions are mediated by the direct interaction between WDR-23 and SKN-1c. To test this, we measured in vivo larval development and resistance to juglone, an electrophile and reactive oxygen species generator $(48,49)$, in $w d r-23(k 1010)$ and $s k n-1(k 1023)$ worms, which encode noninteracting WDR-23(G334R) and SKN-1(R41C) mutant proteins (Fig. 3 and see Fig. S1 in the supplemental material), respectively. Importantly, WDR-23(G334R) also partially reduces protein levels (Fig. 3). As shown in Fig. 7A and B, both strains were highly resistant to juglone and developed slower than N2 wild-type worms
$(P<0.001)$. The developmental delay of $w d r-23(k 1010)$ and $s k n-$ 1 ( $k 1023)$ worms was not as severe as $w d r-23(t m 1817)$-null worms (Fig. 7B). Lastly, we also found that $s k n-1(k 1023)$ increased median longevity by $17 \%(P<0.001$, Fig. $7 \mathrm{C})$. These data indicate that the interaction between SKN-1c and WDR-23 is required for normal rates of larval development, stress resistance, and longevity and also establish $s k n-1(k 1023)$ as the first $s k n-1$ gain-of-function mutation that increases longevity (38).

\section{DISCUSSION}

We previously identified the conserved WD40 repeat protein WDR-23 as a principal repressor of SKN-1 nuclear abundance and activity and demonstrated that SKN-1 regulates itself by activating the expression of $w d r-23(3,8)$. WDR-23 interacts and functions with the DDB-1/CUL-4 ubiquitin ligase, suggesting reg- 

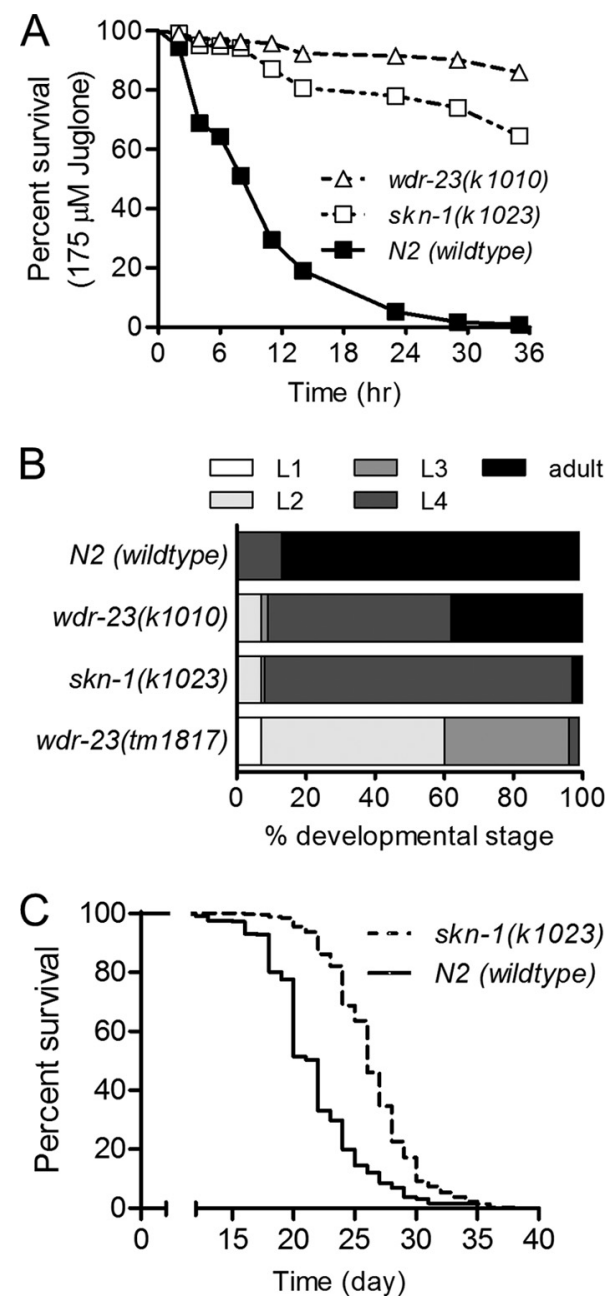

FIG 7 Disruption of the SKN-1-WDR-23 interaction increases stress resistance, promotes longevity, and delays development. (A) Survival of $175 \mu \mathrm{M}$ juglone for N2, wdr-23(k1010) (encoding WDR-23 [G334R]), and skn1 (k1023) (encoding SKN-1c [R41C]) mutants ( $n=349$ to 378 worms from two experiments; $P<0.0001$ for mutants compared to $\mathrm{N} 2$ by $\log$ rank test). (B) Stacked contingency plot of developmental stages of N2, wdr-23(k1010), skn1(k1023), and $w d r-23(\operatorname{tm} 1817)$ mutants $(n=99$ to 105 worms 3 days after placing L1 larvae on food). All strains are different from each other $(P<0.01)$ as determined by chi-square analysis. (C) Longevity of $\mathrm{N} 2$ and $s k n-1(k 1023)$ worms ( $n=251$ to 735 worms from four experiments; $P<0.0001$, as determined by log rank test).

ulation by ubiquitylation and degradation. Here, we provide evidence for preferential regulation of SKN-1c, one of three splice variants with distinct expression and functions. We identify the top surface of WDR-23 and four conserved motifs at the termini of SKN-1c that are required for the interaction. Surprisingly, two of these motifs in SKN-1 were previously found to directly interact with DNA of target gene promoters $(46,50)$, and we found that WDR-23 can block DNA binding by SKN-1c. We also found that simply disrupting the interaction between WDR-23 and SKN-1c with a single amino acid substitution strongly activates the pathway, delays development, and increases stress resistance and longevity. We propose a revised working model based on our results (Fig. 8) and discuss the details below.

WDR-23 may preferentially regulate SKN-1c. Previous stud- ies indicated that splice variants of SKN-1 have important differences in how they are regulated and how and where they function. Although all three variants share a $\mathrm{C}$ terminus, we were unable to detect any interaction between WDR-23 and SKN-1a or SKN-1b in assays that readily detected interaction with SKN-1c (Fig. 1). We also failed to detect any regulation of SKN-1a::GFP or SKN1b::GFP fusion proteins by $w d r-23$ in vivo (Fig. 2). A previous study used WDR-23 as a positive control for co-IP experiments with SKN-1 (38). Interestingly, that study found robust co-IP of WDR-23 with SKN-1c but also found a greatly reduced, yet detectable, co-IP of WDR-23 with SKN-1a. These results are consistent with WDR-23 having a weaker interaction with SKN-1a than SKN-1c but do contradict our inability to detect any pulldown of SKN-1a (Fig. 1). One possible explanation is that the radioactive detection approach used in the prior study is more sensitive than our Western blotting system and was able to detect a weak interaction. Alternatively, it is also possible that a small amount of contaminating SKN-1c was translated from an internal start codon on the C-terminally tagged SKN-1a construct (a possibility with in vitro translation [51]) used in the previous study (38). Regardless, both sets of data at the least support a stronger interaction with SKN-1c than with SKN-1a.

Our data suggest that $w d r-23$ is expressed with SKN-1b in ASI neurons (Fig. 2), supporting the conclusion that cell specific and constitutive expression of SKN-1b relies on its promoter (19) and not a lack of WDR-23 in ASI neurons. How SKN-1b in ASI neurons functions to promote longevity during calorie restriction remains unknown and deserves further attention (19). Taken together, our results suggest that differences in the $\mathrm{N}$ termini of SKN-1 variants may determine preferential regulation by WDR-23.

The interaction between WDR-23 and SKN-1c facilitates regulation of detoxification genes, stress resistance, longevity, and development. We previously demonstrated that the loss of $w d r-23$ increases SKN-1 accumulation in the nucleus, activates detoxification genes, increases stress resistance and longevity, and delays development $(3,8)$, but it was not known whether all of these functions are mediated by the direct interaction. Here, we isolated a panel of $w d r-23$ and $s k n-1$ missense mutations that each constitutively activates the core SKN-1 target gene gst-4 independently of stress (Fig. 3). Three WDR-23 mutations and the single SKN-1 missense mutation all disrupted the interaction between these proteins and caused a dramatic increase in nuclear abundance of endogenous SKN-1c (Fig. 3). Importantly, single amino acid substitutions that disrupt the SKN-1c/WDR-23 interaction also increased stress resistance, increased life span, and delayed development (Fig. 7). To our knowledge, skn-1(k1023), which encodes SKN-1c (R41C), is the first $s k n-1$ allele that increases stress resistance and longevity (38). The $s k n-1(k 1023)$ allele also has a less severe developmental delay than the $w d r$-23(tm1817)-null allele (Fig. 7). Therefore, $s k n-1(k 1023)$ is a valuable model for studying the function of SKN-1 in stress resistance and longevity.

To our knowledge, all WD40 repeat protein structures solved to date form $\beta$-propellers (26). Our homology model of WDR-23 predicts a $\beta$-propeller with seven blades (Fig. 4). Although most of the $w d r$-23 missense mutations mapped to the fourth and fifth blades, residues on the top surfaces of multiple blades were required for the interaction with SKN-1c (Fig. 4). These data are consistent with the top surface of the $\beta$-propeller interacting with SKN-1 (Fig. 4 and 8), which is a common interaction site for WD40 repeat proteins (45). One $w d r-23$ missense mutation 


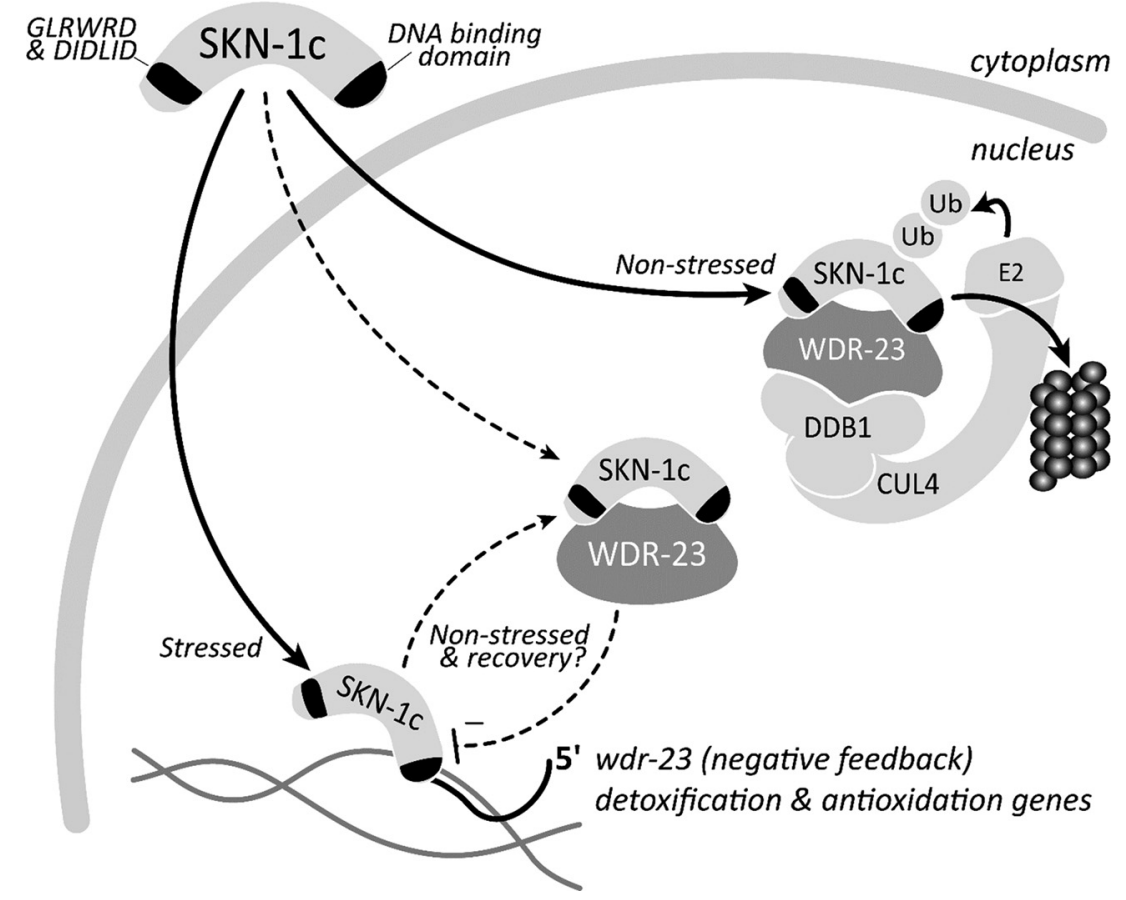

FIG 8 Working model of WDR-23 regulation of SKN-1c. WDR-23 preferentially interacts with and regulates SKN-1c. We previously postulated that SKN-1 constitutively enters the nucleus in nonstressed cells but is prevented from activating genes because it is recruited to the CUL-4/DDB-1 ubiquitin ligase and targeted for destruction. Our current data confirm that WDR-23 strongly represses nuclear accumulation of endogenous SKN-1c and demonstrate that this regulation is dependent on a direct interaction (Fig. 3). Our biochemical data are consistent with the idea that residues in motifs at both termini of SKN-1c (GLRWRD, DIDLID, GQRKR, and KIRRR) interact with the top of WDR-23 (Fig. 4 and 5). Our in vitro DNA binding data (Fig. 6) led us to postulate that WDR-23 can inhibit DNA binding of SKN-1c independently of the ubiquitin proteasome system, which could become occupied or damaged during stress. When active, $\mathrm{SKN}-1 \mathrm{c}$ not only activates genes that promote detoxification and antioxidation but also $w d r-23$, which provides negative feedback by increasing WDR-23 levels (3).

(R342H) mapped to the bottom (Fig. 4), suggesting that this surface may also contribute.

Conserved N-terminal and C-terminal motifs in SKN-1c contribute to the interaction with WDR-23. We found four specific motifs within the termini of SKN-1c that strongly influence the interaction with WDR-23 (Fig. 5). Taken together, these results are consistent with a model in which both termini of SKN-1 interact with WDR-23 (Fig. 8), although we cannot rule out the possibility that direct interaction is more restricted and indirectly influenced via steric changes to other parts of the protein.

At the $\mathrm{N}$ terminus, GLRWRD and DIDLID sequence motifs were required for the interaction. GLRWRD is conserved among nematodes related to C. elegans and is mutated in $s k n-1(k 1023)$. DIDLID is conserved with mammalian Nrf1 and Nrf2 (Fig. 5 and see Fig. S4 in the supplemental material), suggesting that it has more ancient and widespread functions. Although DIDLID was found to be required for SKN-1 transactivation when heterologously expressed in HeLa cells (52), its role in other CNCs is poorly defined. DIDLID is not required for Nrf2 to interact with Keap1, but it does play a role in degradation by an unknown Keap-1-independent mechanism (53). Nrf1 is essential for development (54) and homeostasis in tissues such as skin, brain, and liver (55-57). Nrf1 regulation is poorly defined, but neither of its two known degradation pathways has been reported to involve $\operatorname{DIDLID}(58,59)$. WDR-23 is highly conserved among eukaryotes, but other than interacting with the DDB1/CUL4 ligase $(60,61)$, nothing is known about its function outside of $C$. elegans. The involvement of DIDLID with WDR-23 raises the possibility that WDR-23 regulation of CNCs is widespread. Affinity capture and proteomic studies are needed to identify binding partners for WDR23 in organisms outside of nematodes.

Two mechanisms with one propeller? The importance of the SKN-1 C terminus to the interaction with WDR-23 is surprising given that this domain is the well-characterized DNA-binding domain $(46,50)$. Our finding that interacting with WDR-23 inhibits DNA binding by SKN-1c (Fig. 6) suggests a novel mechanism of $\mathrm{SKN}-1 \mathrm{c}$ regulation. Although distinguishing the biological relevance of this mechanism from the ubiquitin ligase mechanism (8) is problematic because of the dramatic influence of WDR-23 on SKN-1c nuclear abundance (Fig. 3), our data are consistent with a model in which WDR-23 could inhibit SKN-1c independently of the DDB-1/CUL-4 ubiquitin ligase. This revised working model (Fig. 8) is also consistent with our previous data showing that silencing of $w d r-23$ causes a far greater (5- to 7-fold) activation of SKN-1-regulated promoter reporters than silencing of $d d b-1$, cul-4, or proteasome subunits (8) and with previous studies that demonstrated that SKN-1 accumulation can occur independently of target gene promoter activation $(15,18,29)$.

WD40 proteins are known to regulate gene transcription by controlling the stability of transcriptional regulators or by recruiting chromatin remodeling factors $(26,28)$. Here, we provide evidence of a WD40 repeat protein directly inhibiting DNA binding by a transcription factor. This alternative mechanism has the advantage of not requiring the ubiquitin proteasome system, which 
could become occupied with other signaling and damaged protein substrates during cellular stress (62). It could also allow SKN-1c to be removed from chromatin as a mechanism for terminating the response during recovery (Fig. 8).

\section{ACKNOWLEDGMENTS}

Some C. elegans strains were provided by the Caenorhabditis Genetics Center (University of Minnesota, Minneapolis, MN).

All authors participated in proposing, designing, and performing the experiments and in analysis and interpretation of data. C.K.L. and K.P.C. wrote the manuscript, and all authors approved the final version for publication.

This study was funded by NSF grant IOS-1120130 to K.P.C. and a Grant-in-Aid for Scientific Research of MEXT to J.M.

\section{REFERENCES}

1. Sykiotis G, Bohmann D. 2010. Stress-activated cap'n'collar transcription factors in aging and human disease. Sci. Signal. 3:re3.

2. Wakabayashi N, Itoh K, Wakabayashi J, Motohashi H, Noda S, Takahashi S, Imakado S, Kotsuji T, Otsuka F, Roop DR, Harada T, Engel JD, Yamamoto M. 2003. Keap1-null mutation leads to postnatal lethality due to constitutive Nrf2 activation. Nat. Genet. 35:238-245. http://dx.doi.org $/ 10.1038 / \mathrm{ng} 1248$.

3. Leung CK, Wang Y, Deonarine A, Tang L, Prasse S, Choe KP. 2013. A negative feedback loop between the detoxification/antioxidant response factor SKN-1 and its repressor WDR-23 matches organism needs with environmental conditions. Mol. Cell. Biol. 33:3524-3537. http://dx.doi .org/10.1128/MCB.00245-13.

4. Lee O-H, Jain AK, Papusha V, Jaiswal AK. 2007. An auto-regulatory loop between stress sensors INrf2 and Nrf2 controls their cellular abundance. J. Biol. Chem. 282:36412-36420. http://dx.doi.org/10.1074/jbc .M706517200.

5. Bryan HK, Olayanju A, Goldring CE, Park BK. 2013. The Nrf2 cell defence pathway: Keap1-dependent and -independent mechanisms of regulation. Biochem. Pharmacol. 85:705-717. http://dx.doi.org/10.1016/j .bcp.2012.11.016.

6. An JH, Vranas $\mathrm{K}$, Lucke $\mathrm{M}$, Inoue $\mathrm{H}$, Hisamoto $\mathrm{N}$, Matsumoto $\mathrm{K}$, Blackwell TK. 2005. Regulation of the Caenorhabditis elegans oxidative stress defense protein SKN-1 by glycogen synthase kinase-3. Proc. Natl. Acad. Sci. U. S. A. 102:16275-16280. http://dx.doi.org/10.1073/pnas .0508105102 .

7. An JH, Blackwell TK. 2003. SKN-1 links C. elegans mesendodermal specification to a conserved oxidative stress response. Genes Dev. 17:18821893. http://dx.doi.org/10.1101/gad.1107803.

8. Choe KP, Przybysz AJ, Strange K. 2009. The WD40 repeat protein WDR-23 functions with the CUL4/DDB1 ubiquitin ligase to regulate nuclear abundance and activity of SKN-1 in Caenorhabditis elegans. Mol. Cell. Biol. 29:2704-2715. http://dx.doi.org/10.1128/MCB.01811-08.

9. Lee J-S, Surh Y-J. 2005. Nrf2 as a novel molecular target for chemoprevention. Cancer Lett. 224:171-184. http://dx.doi.org/10.1016/j.canlet 2004.09.042.

10. Satoh T, Okamoto S-i, Cui J, Watanabe Y, Furuta K, Suzuki M, Tohyama K, Lipton SA. 2006. Activation of the Keap1/Nrf2 pathway for neuroprotection by electrophilic phase II inducers. Proc. Natl. Acad. Sci. U. S. A. 103:768-773. http://dx.doi.org/10.1073/pnas.0505723102.

11. Kundu JK, Surh YJ. 2010. Nrf2-Keap1 signaling as a potential target for chemoprevention of inflammation-associated carcinogenesis. Pharm. Res. 27:999-1013. http://dx.doi.org/10.1007/s11095-010-0096-8.

12. Bowerman B, Eaton BA, Priess JR. 1992. $s k n-1$, a maternally expressed gene required to specify the fate of ventral blastomeres in the early Caenorhabditis elegans embryo. Cell 68:1061-1075. http://dx.doi.org/10.1016 /0092-8674(92)90078-Q.

13. Tullet JMA, Hertweck M, An JH, Baker J, Hwang JY, Liu S, Oliveira RP, Baumeister R, Blackwell TK. 2008. Direct inhibition of the longevitypromoting factor SKN-1 by insulin-like signaling in Caenorhabditis elegans. Cell 132:1025-1038. http://dx.doi.org/10.1016/j.cell.2008.01.030.

14. Wang J, Robida-Stubbs S, Tullet JM, Rual JF, Vidal M, Blackwell TK. 2010. RNAi screening implicates a SKN-1-dependent transcriptional response in stress resistance and longevity deriving from translation inhibition. PLoS Genet. 6:e1001048. http://dx.doi.org/10.1371/journal.pgen .1001048 .
15. Robida-Stubbs S, Glover-Cutter K, Lamming DW, Mizunuma $M$, Narasimhan SD, Neumann-Haefelin E, Sabatini DM, Blackwell TK. 2012. TOR signaling and rapamycin influence longevity by regulating SKN-1/Nrf and DAF-16/FoxO. Cell Metab. 15:713-724. http://dx.doi.org /10.1016/j.cmet.2012.04.007.

16. Choe KP, Leung CK, Miyamoto MM. 2012. Unique structure and regulation of the nematode detoxification gene regulator, SKN-1: implications to understanding and controlling drug resistance. Drug Metab. Rev. 44:209-223. http://dx.doi.org/10.3109/03602532.2012.684799.

17. Leung CK, Wang Y, Malany S, Deonarine A, Nguyen K, Vasile S, Choe KP. 2013. An ultra-high-throughput, whole-animal screen for small molecule modulators of a specific genetic pathway in Caenorhabditis elegans. PLoS One 8:e62166. http://dx.doi.org/10.1371/journal.pone.0062166.

18. Glover-Cutter KM, Lin S, Blackwell TK. 2013. Integration of the unfolded protein and oxidative stress responses through SKN-1/Nrf. PLoS Genet. 9:e1003701. http://dx.doi.org/10.1371/journal.pgen.1003701.

19. Bishop NA, Guarente L. 2007. Two neurons mediate diet-restrictioninduced longevity in Caenorhabditis elegans. Nature 447:545-549. http: //dx.doi.org/10.1038/nature05904.

20. Inoue $\mathrm{H}$, Hisamoto $\mathrm{N}$, An JH, Oliveira RP, Nishida E, Blackwell TK, Matsumoto K. 2005. The Caenorhabditis elegans p38 MAPK pathway regulates nuclear localization of the transcription factor SKN-1 in oxidative stress response. Genes Dev. 19:2278-2283. http://dx.doi.org/10.1101 /gad.1324805.

21. Kell A, Ventura N, Kahn N, Johnson TE. 2007. Activation of SKN-1 by novel kinases in Caenorhabditis elegans. Free Rad Biol. Med. 43:15601566. http://dx.doi.org/10.1016/j.freeradbiomed.2007.08.025.

22. Okuyama $T$, Inoue $H$, Ookuma $S$, Satoh $T$, Kano $K$, Honjoh $S$, Hisamoto N, Matsumoto K, Nishida E. 2010. The ERK-MAPK pathway regulates longevity through SKN-1 and insulin-like signaling in Caenorhabditis elegans. J. Biol. Chem. 285:30274-30281. http://dx.doi.org/10 .1074 /jbc.M110.146274.

23. Hasegawa K, Miwa J. 2010. Genetic and cellular characterization of Caenorhabditis elegans mutants abnormal in the regulation of many phase II enzymes. PLoS One 5:e11194. http://dx.doi.org/10.1371/journal.pone .0011194 .

24. Hasegawa K, Miwa J. 2010. Transcriptome analysis of the xrep-1(RNAi) phenocopy in Caenorhabditis elegans. Annu. Rep. Res. Inst. Biol. Funct. 10:72-80.

25. Staab TA, Griffen TC, Corcoran C, Evgrafov O, Knowles JA, Sieburth D. 2013. The conserved SKN-1/Nrf2 stress response pathway regulates synaptic function in Caenorhabditis elegans. PLoS Genet. 9:e1003354. http://dx.doi.org/10.1371/journal.pgen.1003354.

26. Stirnimann CU, Petsalaki E, Russell RB, Muller CW. 2010. WD40 proteins propel cellular networks. Trends Biochem. Sci. 35:565-574. http: //dx.doi.org/10.1016/j.tibs.2010.04.003.

27. Suganuma T, Workman JL. 2010. WD40 repeats arrange histone tails for spreading of silencing. J. Mol. Cell. Biol. 2:81-83. http://dx.doi.org/10 $.1093 / \mathrm{jmcb} / \mathrm{mjp} 046$.

28. Migliori V, Mapelli M, Guccione E. 2012. On WD40 proteins: propelling our knowledge of transcriptional control? Epigenetics 7:815-822. http: //dx.doi.org/10.4161/epi.21140.

29. Kahn NW, Rea SL, Moyle S, Kell A, Johnson TE. 2008. Proteasomal dysfunction activates the transcription factor SKN-1 and produces a selective oxidative-stress response in Caenorhabditis elegans. Biochem. J. 409:205-213. http://dx.doi.org/10.1042/BJ20070521.

30. Brenner S. 1974. The genetics of Caenorhabditis elegans. Genetics 77:71-94.

31. Maine EM, Kimble J. 1989. Identification of genes that interact with $g l p-1$, a gene required for inductive cell interactions in Caenorhabditis elegans. Dev. 106:133-143.

32. Abramoff MD, Magelhaes PJ, Ram SJ. 2004. Image processing with ImageJ. Biophotonics Int. 11:36-42.

33. Hasegawa K, Miwa S, Tsutsumiuchi K, Miwa J. 2010. Allyl isothiocyanate that induces GST and UGT expression confers oxidative stress resistance on Caenorhabditis elegans, as demonstrated by nematode biosensor. PLoS One 5:e9267. http://dx.doi.org/10.1371/journal.pone.0009267.

34. Tops BB, Tabara H, Sijen T, Simmer F, Mello CC, Plasterk RH, Ketting RF. 2005. RDE-2 interacts with MUT-7 to mediate RNA interference in Caenorhabditis elegans. Nucleic Acids Res. 33:347-355. http://dx.doi.org /10.1093/nar/gki183.

35. Kelley LA, Sternberg MJ. 2009. Protein structure prediction on the Web: a case study using the Phyre server. Nat. Protoc. 4:363-371. http://dx.doi .org/10.1038/nprot.2009.2. 
36. Hall DH, Altun ZF. 2008. Caenorhabditis elegans atlas. Cold Spring Harbor Laboratory Press, Cold Spring Harbor, NY.

37. Oliveira RP, Abate JP, Dilks K, Landis J, Ashraf J, Murphy CT, Blackwell TK. 2009. Condition-adapted stress and longevity gene regulation by Caenorhabditis elegans SKN-1/Nrf. Aging Cell 8:524-541. http://dx.doi .org/10.1111/j.1474-9726.2009.00501.x.

38. Paek J, Lo JY, Narasimhan SD, Nguyen TN, Glover-Cutter K, RobidaStubbs S, Suzuki T, Yamamoto M, Blackwell TK, Curran SP. 2012. Mitochondrial SKN-1/Nrf mediates a conserved starvation response. Cell Metab. 16:526-537. http://dx.doi.org/10.1016/j.cmet.2012.09.007.

39. Leung CK, Empinado H, Choe KP. 2012. Depletion of a nucleolar protein activates xenobiotic detoxification genes in Caenorhabditis elegans via Nrf/SKN-1 and p53/CEP-1. Free Radic. Biol. Med. 52:937-950. http: //dx.doi.org/10.1016/j.freeradbiomed.2011.12.009.

40. Bowerman B, Draper BW, Mello CC, Priess JR. 1993. The maternal gene skn-1 encodes a protein that is distributed unequally in early Caenorhabditis elegans embryos. Cell 74:443-452. http://dx.doi.org/10.1016/0092 -8674(93)80046-H.

41. Arnold K, Bordoli L, Kopp J, Schwede T. 2006. The SWISS-MODEL workspace: a web-based environment for protein structure homology modeling. Bioinformatics 22:195-201. http://dx.doi.org/10.1093/bioinformatics /bti770.

42. Bordoli L, Kiefer F, Arnold K, Benkert P, Battey J, Schwede T. 2009. Protein structure homology modeling using SWISS-MODEL workspace. Nat. Protoc. 4:1-13.

43. Kiefer F, Arnold K, Kunzli M, Bordoli L, Schwede T. 2009. The SWISSMODEL repository and associated resources. Nucleic Acids Res. 37: D387-D392. http://dx.doi.org/10.1093/nar/gkn750.

44. Bordoli L, Schwede T. 2012. Automated protein structure modeling with SWISS-MODEL workspace and the protein model portal. Methods Mol. Biol. 857:107-136. http://dx.doi.org/10.1007/978-1-61779-588-6_5.

45. Wu XH, Wang Y, Zhuo Z, Jiang F, Wu YD. 2012. Identifying the hot spots on the top faces of WD40-repeat proteins from their primary sequences by beta-bulges and DHSW tetrads. PLoS One 7:e43005. http://dx .doi.org/10.1371/journal.pone.0043005.

46. Rupert PB, Daughdrill GW, Bowerman B, Matthews BW. 1998. A new DNA-binding motif in the Skn-1 binding domain-DNA complex. Nat. Struct. Biol. 5:484-491. http://dx.doi.org/10.1038/nsb0698-484.

47. Curran SP, Ruvkun G. 2007. Lifespan regulation by evolutionarily conserved genes essential for viability. PLoS Genet. 3:e56. http://dx.doi.org/10 .1371/journal.pgen.0030056.

48. Rodriguez CE, Shinyashiki M, Froines J, Yu RC, Fukuto JM, Cho AK. 2004. An examination of quinone toxicity using the yeast Saccharomyces cerevisiae model system. J. Toxicol. 201:185-196. http://dx.doi.org/10 .1016/j.tox.2004.04.016.

49. Aithal KB, Kumar S, Rao BN, Udupa N, Rao SB. 2011. Tumor growth inhibitory effect of juglone and its radiation sensitizing potential: in vivo and in vitro studies. Integr. Cancer Ther. 11:68-80. http://dx.doi.org/10 $.1177 / 1534735411403477$.

50. Blackwell TK, Bowerman B, Priess JR, Weintraub H. 1994. Formation of a monomeric DNA binding domain by SKN-1 bZIP and homeodomain elements. Science 266:621-628. http://dx.doi.org/10.1126/science.7939715.

51. Brouette C, Betz N, Kobs G. 2002. Optimized gene expression with the T7 sample system. Promega Notes 80:10-13.

52. Walker AK, See R, Batchelder C, Kophengnavong T, Gronniger JT, Shi Y, Blackwell TK. 2000. A conserved transcription motif suggesting functional parallels between Caenorhabditis elegans SKN-1 and cap'n'collarrelated basic leucine zipper proteins. J. Biol. Chem. 275:22166-22171. http://dx.doi.org/10.1074/jbc.M001746200.

53. McMahon M, Thomas N, Itoh K, Yamamoto M, Hayes JD. 2004 Redox-regulated turnover of Nrf2 is determined by at least two separate protein domains, the redox-sensitive neh 2 degron and the redoxinsensitive neh6 degron. J. Biol. Chem. 279:31556-31567. http://dx.doi .org/10.1074/jbc.M403061200

54. Chan JY, Kwong M, Lu R, Chang J, Wang B, Yen TSB, Kan YW. 1998. Targeted disruption of the ubiquitous CNC-bZIP transcription factor, Nrf-1, results in anemia and embryonic lethality in mice. EMBO J. 17: 1779-1787. http://dx.doi.org/10.1093/emboj/17.6.1779.

55. Han W, Ming M, Zhao R, Pi J, Wu C, He YY. 2012. Nrf1 CNC-bZIP protein promotes cell survival and nucleotide excision repair through maintaining glutathione homeostasis. J. Biol. Chem. 287:18788-18795. http://dx.doi.org/10.1074/jbc.M112.363614

56. Chen L, Kwong M, Lu R, Ginzinger D, Lee C, Leung L, Chan JY. 2003. Nrf1 is critical for redox balance and survival of liver cells during development. Mol. Cell. Biol. 23:4673-4686. http://dx.doi.org/10.1128/MCB 23.13.4673-4686.2003

57. Lee CS, Lee C, Hu T, Nguyen JM, Zhang J, Martin MV, Vawter MP, Huang EJ, Chan JY. 2011. Loss of nuclear factor E2-related factor 1 in the brain leads to dysregulation of proteasome gene expression and neurodegeneration. Proc. Natl. Acad. Sci. U. S. A. 108:8408-8413. http://dx.doi .org/10.1073/pnas.1019209108.

58. Biswas M, Phan D, Watanabe M, Chan JY. 2011. The Fbw7 tumor suppressor regulates nuclear factor E2-related factor 1 transcription factor turnover through proteasome-mediated proteolysis. J. Biol. Chem. 286: 39282-39289. http://dx.doi.org/10.1074/jbc.M111.253807.

59. Tsuchiya Y, Morita T, Kim M, Iemura S, Natsume T, Yamamoto M, Kobayashi A. 2011. Dual regulation of the transcriptional activity of Nrf1 by beta-TrCP- and Hrd1-dependent degradation mechanisms. Mol. Cell. Biol. 31:4500-4512. http://dx.doi.org/10.1128/MCB.05663-11.

60. Angers S, Li T, Yi X, MacCoss MJ, Moon RT, Zheng N. 2006. Molecular architecture and assembly of the DDB1-CUL4A ubiquitin ligase machinery. Nature 443:590-593. http://dx.doi.org/10.1038/nature05175.

61. Lee J-H, Terzaghi W, Gusmaroli G, Charron J-BF, Yoon H-J, Chen H, He YJ, Xiong Y, Deng XW. 2008. Characterization of Arabidopsis and rice DWD proteins and their roles as substrate receptors for CUL4-RING E3 ubiquitin ligases. Plant Cell 20:152-167. http://dx.doi.org/10.1105/tpc .107 .055418 .

62. Aiken CT, Kaake RM, Wang X, Huang L. 2011. Oxidative stressmediated regulation of proteasome complexes. Mol. Cell. Proteomics 10: R110.006924. http://dx.doi.org/10.1074/mcp.M110.006924. 